\title{
Vasodilatation induced by forskolin involves cyclic GMP production
}

\author{
Mário dos Anjos Neto ${ }^{1 *}$, Claure Nain Lunardi ${ }^{2}$, Gerson Jhonatan Rodrigues ${ }^{3}$, \\ Lusiane Maria Bendhack ${ }^{4}$
}

\footnotetext{
${ }^{1}$ Faculdade Ingá-Uningá, Maringá, Brazil; *Corresponding Author: marioneto@uninga.br

${ }^{2}$ Faculdade de Ceilândia, University of Brasilia, Brasilia, Brazil;

${ }^{3}$ Department of Pharmacology, Faculty of Medicine, University of São Paulo, Ribeirão Preto, Brazil;

${ }^{4}$ Department of Physics and Chemistry, Faculty of Pharmaceutical Sciences of Ribeirão Preto, University of São Paulo, Ribeirão Preto, Brazil.
}

Received 30 June 2011; revised 5 August 2011; accepted 20 August 2011.

\begin{abstract}
Endothelium-derived relaxing factors contribute to smooth muscle relaxation. The aim of the present study was to investigate the contribution of nitric oxide (NO) produced in the endothelial cells to the vasodilatation stimulated with forskolin in rat aorta. Forskolin that directly activates adenylyl-cyclase, induced complete relaxation in phenylephrine-contracted aortas. Endothelium removal reduced the potency $\left(\mathrm{pEC}_{50}\right)$ of forskolin without changes in the maximum effect (Emax). However, the inhibitor of endothelial NO-synthase (10 $\mu \mathrm{M}$ L-NG-Nitroarginine, LNNA) reduced both Emax and $\mathrm{pEC}_{50}$ in intact endothelium aortic rings. L-NNA or L-NNA plus cyclooxygenase inhibitor indomethacin $(10 \mu \mathrm{M})$ reduced both Emax and $p E C_{50}$ of forskolin. Forskolin increased both the cytosolic $\mathrm{Ca}^{2+}$ concentration and the cytosolic NO concentration ([NO]c) in the endothelial cells. The PKA inhibitor KT5720 reduced the NO production activated by forskolin in the endothelial cells. The enhanced [NO]c in the endothelial cells increased cyclic guanosine-monophosphate (cGMP) in smooth muscle cells, which was abolished by L-NNA. Taken together, our results indicate that vasodilatation mediated by forskolin in rat aortic rings is potentiated by NO production in endothelial cells that increases the cGMP levels in the smooth muscle cells that along with cAMP contribute to the vasodilatation.
\end{abstract}

Keywords: Forskolin; Cytosolic Calcium; CAMP; cGMP; Endothelial Cells; Nitric Oxide

\section{INTRODUCTION}

Intracellular levels of cyclic nucleotide 3'-5' cyclic monophosphate adenosine (cAMP) are regulated through its synthesis by adenylyl cyclase [1]. Forskolin, a diterpen obtained from Coleus forskohlii, can activate all the isoforms of adenylyl cyclase by binding to its catalytic subunit resulting in cAMP production $[2,3]$.

It has been reported that forskolin directly mediates the vasodilatation activating adenylyl-cyclase on the vascular smooth muscle cells [3-5]. This effect is due to activation of protein kinase-A (PKA) that can phosphorylate several proteins involved in various effects such as 1) inhibition of $\mathrm{Ca}^{2+}$ influx across the plasma membrane [6]; 2) increase of $\mathrm{Ca}^{2+}$ uptake into the sarcoplasmic reticulum [7]; 3) inhibition of myosin light chain kinase [8]; 4) activation of $\mathrm{Ca}^{2+}$ efflux from the smooth muscle cells [9].

A large amount of potential compounds which could produce NO via cAMP has been investigated. NO can be synthesized by three distinct isoforms of NO-synthases, a constitutive $\mathrm{Ca}^{2+}$ - and calmodulin-dependent soluble form that is present mainly in neural tissues (nNOS), an inducible $\mathrm{Ca}^{2+}$-independent form that is inducible by endotoxin or certain cytokines (iNOS) or a constitutive $\mathrm{Ca}^{2+}-$ and calmodulin-dependent membrane-bound isoform (eNOS) present in the endothelial cells and that plays an important role in the dynamic control of vascular tone [10-12] because NO produced in the endothelial cells activates the production of cGMP in the vascular smooth muscle cells and induces vasodilatation.

As reported by Moncada and Vane (1979) [13] the smooth muscle cells are able to generate $\mathrm{PGI}_{2}$, and the arterial endothelial cells synthesize this factor three or ten times more than the venous endothelium. In the same way, Samokovlisky et al. (1999) [14] have shown that the increase of cAMP in bovine aortic endothelial cells inhibits $\mathrm{PGI}_{2}$ production, an effect that is suppressed by cAMP inhibition.

Therefore, the aim of the present study was to investi- 
gate the contribution of NO produced in the endothelial cells to the vasodilatation stimulated with forskolin in rat aorta.

\section{MATERIAL AND METHODS}

\subsection{Vascular Reactivity Studies}

Male Male Wistar rats (180 - $200 \mathrm{~g})$ were anesthetized and killed by decapitation and the thoracic aortas were isolated. Aortic rings, $4 \mathrm{~mm}$ in length, were placed in bath chambers $(10 \mathrm{~mL})$ for isolated organs containing physiological salt solution (PSS) at $37^{\circ} \mathrm{C}$, continuously bubbled with $95 \% \mathrm{O}_{2}$ and $5 \% \mathrm{CO}_{2}, \mathrm{pH}$ 7.4. The system was connected to an F-60 force-displacement transducer, and the contractile responses were recorded on a polygraph (Narco Biosystems Inc., Houston-TX). The aortic rings were submitted to a tension of $1.5 \mathrm{~g}$, which was readjusted every $15 \mathrm{~min}$ throughout a 60 -min equilibration period before the addition of the given drug. An optimal basal tension of $1.5 \mathrm{~g}$ was previously standardized by exposing the vessels to $90 \mathrm{mM} \mathrm{KCl}$ under various resting tensions $(0.25-2.5 \mathrm{~g})$. All the procedures were in accordance with the Ethical Animal Committee of the University of São Paulo, Brazil.

At the beginning of the experiments, the aortas were stimulated with $1 \mu \mathrm{M}$ norepinephrine to test their functional integrity. In some preparations, the endothelium was mechanically removed by gently rubbing the intimal surface with stainless steel holders. The integrity of the endothelium was tested with acetylcholine $(1 \mu \mathrm{M})$. Endothelium removal was confirmed by lack of acetylcholine-induced relaxation.

After the endothelial integrity was assessed, aortic rings were pre-contracted with $100 \mathrm{nM}$ phenylephrine. When the plateau was reached, concentration-effect curves to forskolin $(0.1 \mathrm{nM}$ to $1 \mu \mathrm{M})$ were constructed in the absence or in presence of eNOS inhibitor L-NNA (10 $\mu \mathrm{M})$, cyclooxigenase inhibitor indomethacin $(10 \mu \mathrm{M})$ or the combination of both inhibitors in the same concentrations used alone.

\section{2. $\mathrm{Ca}^{2+}$ Imaging with Fluorescent Probe}

Briefly, the aortas were dissected and longitudinally opened and endothelium cells were isolated by gently rake friction in Hanks solution. The resulting cells solution was centrifuged at $200 \mathrm{xg}$ and suspended in Hanks solution. The cells were placed on glass coverslips and kept in a humidified $37^{\circ} \mathrm{C}$ incubator gassed with $5 \% \mathrm{CO}_{2}$ for $4 \mathrm{~h}$. The cells were then loaded with $5 \mu \mathrm{M}$ Fura-2AM in $1 \mathrm{mg} / \mathrm{mL}$ BSA for $40 \mathrm{~min}$ at $37^{\circ} \mathrm{C}$. Excess dye was removed by washing out the dye with bath solution for $20 \mathrm{~min}$ for intracellular desterification of Fura-2AM.
Dishes containing Fura-2AM loaded cells were placed in a temperature-regulated $\left(37^{\circ} \mathrm{C}\right)$ chamber mounted on the Nikon inverted microscope [15]. The fluorescence measurement was performed by the window of a dual wavelength spectrofluorimeter (Deltaram, Photon Technology Intl), at excitation wavelengths of $340 \mathrm{~nm}$ and $380 \mathrm{~nm}$ and an emission wavelength of $510 \mathrm{~nm}$.

Fura-2 fluorescent signals originated from the cells stimulated with forskolin $(1 \mu \mathrm{M})$ were collected and stored using a software package from Photon Technology International (Felix). The cells that showed fluorescence above $4 \times 10^{5}$ counts were used. Fura- 2 ratio corrected for background fluorescence was converted to $\left[\mathrm{Ca}^{2+}\right]_{\mathrm{c}}$ by the ratio between the two excitation wavelengths (340 and $380 \mathrm{~nm}$ ) in which Fura-2 fluorescence and measured at $510 \mathrm{~nm}$. Fluorescence emission was collected from the single cell. However, at least three independent experiments were performed using separate cells. Because of the recognized uncertainties inherent to the measurement of absolute $\left[\mathrm{Ca}^{2+}\right]_{\mathrm{c}}$, in this study the results are expressed as the $\mathrm{R} 340 / 380 \mathrm{~nm}$ ratio of fluorescence.

\subsection{Nitric Oxide (NO) Measurements}

\subsubsection{Confocal Microscopy and Image Analysis}

The endothelial cells were plated on glass coverslips and kept in a humidified $37^{\circ} \mathrm{C}$ incubator gassed with $5 \%$ $\mathrm{CO}_{2}$. The cells were used $3 \mathrm{~h}$ after plating and were maintained in a serum-free medium. To assess the cytosolic $\mathrm{NO}$ concentration $\left([\mathrm{NO}]_{\mathrm{c}}\right)$, endothelial cells were loaded with 4,5-diaminofluorescein-2 diacetate (DAF-2/DA) (1 $\mu \mathrm{M}$ ) for $30 \mathrm{~min}$ at room temperature on the day of the experiment $[16,17]$. Excess dye was removed by washing the dye out with bath solution and allowing $30 \mathrm{~min}$ for intracellular desterification of DAF2/DA to DAF-2. The cells were imaged in Hanks buffer (pH 7.4). [NO] $]_{\mathrm{c}}$ was assessed by a confocal scanning laser microscope (Leica TCS SP5). DAF-2 fluorescence was excited with the 488-nm line of an argon ion laser, and the emitted fluorescence was measured at $515 \mathrm{~nm}$. A time-course software was used to capture images of the cells at cells at 2 sec intervals (xyt) in the Live Data Mode acquisition. By using the LSCM computer software, the intensities of the intracellular maximal or minimal fluorescence was measured. The initial fluorescence intensity value at $t=0$ sec as taken as $F_{0}$, and the final fluorescence intensity obtained after stimulation with $1 \mu \mathrm{M}$ forskolin was designated $\mathrm{F}$. In this way, the percentage of the difference in fluorescence intensity $(\% \Delta \mathrm{F})$, which reflects the increase in $[\mathrm{NO}] \mathrm{c}$, was obtained for each protocol in relation to the control $(100 \%): \% \Delta \mathrm{F}=\mathrm{F} / \mathrm{F}_{0} \times 100$, where $\mathrm{F}_{0}=$ DAF-2 basal fluorescence intensity and $F=D A F-2 T$ fluorescence intensity after stimulation of the endothelial 
cells with forskolin $(1 \mu \mathrm{M})$. A similar protocol was applied with pre-incubation with L-NNA $(10 \mu \mathrm{M})$ for 5 min.

\subsubsection{Flow Cytometry}

Cytofluorographic analysis was performed by using a FACScan (Becton-Dickinson, San Jose-CA) with an argon ion laser tuned to $488 \mathrm{~nm}$ at $15 \mathrm{~mW}$ output. The cells were analyzed at the flow cytometer without DAF2/DA. Before the detection of NO, the cells were analysed on the flow cytometer. Then, the cells were loaded with the selective NO fluorescent dye (DAF-2/ DA $10 \mu \mathrm{M}$ ) for $20 \mathrm{~min}$ (Blank). After that, the cells loaded with DAF-2/DA were stimulated with forskolin $(1 \mu \mathrm{M})$ and analyzed at zero, $5 \mathrm{~min}$ and $10 \mathrm{~min}$. Similar protocol was performed in the presence of the selective PKA inhibitor KT5720 $(10 \mu \mathrm{M})$. The inhibitor was added to the endothelial cells solution 10 min prior to the addition of DAF-2/ DA. All the steps were performed in zero- $\mathrm{Ca}^{2+}$ medium to exclude the role of PKA on $\mathrm{Ca}^{2+}$ channels and consequent activation of NO production by $\mathrm{Ca}^{2+}$-dependent mechanism. Acquisition was set at 10,000 cells and the mean fluorescence intensity was measured in all samples by using CellQuest 1.2 software (Becton-Dickinson, Franklin Lakes, NJ). The mean fluorescence intensity (FI) for cells was expressed with DAF-2/DA (blank) and cells loaded with DAF-2/DA in the presence of forskolin $(1 \mu \mathrm{M})$, and KT5720 $(10 \mu \mathrm{M})$ plus forskolin $(1$ $\mu \mathrm{M})$.

\subsection{Measurement of cGMP Content}

In order to measure cGMP tissue content, intact rat aortas were incubated with sildenafil $(1 \mu \mathrm{mol} / \mathrm{L})$ for $30 \mathrm{~min}$. The vessels were the exposed to $0.1 \mu \mathrm{M}$ phenylephrine for $10 \mathrm{~min}$ or to $0.1 \mu \mathrm{M}$ phenylephrine for $10 \mathrm{~min}$ followed by a 10-min exposure to forskolin $(1 \mu \mathrm{M})$. In another set of experiments, L-NG-Nitroarginine (L-NNA $10 \mu \mathrm{M}$ ) was incubated for $10 \mathrm{~min}$ and the vessel was exposed to phenylephrine $(0.1 \mu \mathrm{M})$ for $10 \mathrm{~min}$, followed by a $10-\mathrm{min}$ exposure to forskolin $(1 \mu \mathrm{M})$. This was the concentration of forskolin that produced maximum relaxation (Emax) of the aortic rings. The vessel segments were rapidly frozen in liquid nitrogen, homogenized in $6 \%$ trichloroacetic acid, and centrifuged. The supernatant was extracted with water-saturated diethyl ether for six times. The samples were then evaporated under nitrogen and the cGMP content was assayed in duplicate by using a commercially available enzyme-immunoassay kit (Amersham Biosciences). Basal cGMP was defined as the cGMP content obtained without stimulation in the homogenized vessel containing intact endothelium. Results are expressed as fentomoles of cGMP per milligram of protein. Protein was determined by using the Folin Ciocaulteau method.

\subsection{Drugs and Solutions}

Acetylcholine, Albumin bovine fraction V, fatty acidfree, Albumin bovine fraction V, Dimethyl sulfoxide (Grade I) DMSO, Forskolin (HPLC grade), Indomethacin, Norepinephrine, Phenylephrine hydrochloride, $N^{\mathrm{G}}$ nitro-L-arginine (L-NNA), and Poly-L-lysine solution were obtained from Sigma. DAF-2DA was purchased from Sigma Chem. Co. (St Louis, MO). Fura-2AM was obtained from Molecular Probes (Eugene, OR). The enzy me-immunoassay Biotrak (EIA) System for measurement of cGMP content was supplied by Amersham Biosciences (GE Healthcare).

The PSS composition was the following (in $\mathrm{mM}$ ): $130.0 \mathrm{NaCl}, 1.6 \mathrm{CaCl}_{2}, 4.7 \mathrm{KCl}, 1.17 \mathrm{MgSO}_{4}, 1.18$ $\mathrm{KH}_{2} \mathrm{PO}_{4}, 14.9 \mathrm{NaHCO}_{3}, 0.026$ EDTA, and 5.5 dextrose. The Hanks solution composition was as follows (in $\mathrm{mM}$ ): $145.0 \mathrm{NaCl}, 1.6 \mathrm{CaCl}_{2}$ (or without $\mathrm{CaCl}_{2}$ ), $5.0 \mathrm{KCl}, 1.0$ $\mathrm{MgCl}_{2}, 0.5 \mathrm{NaH}_{2} \mathrm{PO}_{4}, 10.0$ dextrose, and 10.0 HEPES.

\subsection{Statistical Analysis}

The forskolin relaxant effect was measured from the plateau of the contraction induced by phenylephrine and expressed as percent relaxation. The maximum effect (Emax) was considered as the maximal amplitude response reached in the concentration-effect curves for forskolin. The forskolin concentration that produced halfmaximal relaxation amplitude $\left(\mathrm{EC}_{50}\right)$ was determined and is expressed as $\mathrm{pEC}_{50}$. The $\mathrm{pEC}_{50}$ value is the negative logarithm and expressed as $\log$ molar $\mathrm{EC}_{50}$. Data analysis and figure plots were carried out with the aid of software GraphPad PRISM ${ }^{\mathrm{TM}}$, Version 3.02 (2000) (San Diego, CA). Data are expressed as mean \pm SEM. In each set of experiments, $n$ indicates the number of tissues stu- died. Differences between mean values have been as- sessed either by Student's $t$-test or by one-way analysis of variance (ANOVA), followed by a Newman-Keuls post-hoc test. Values of $\mathrm{P}<0.05$ were considered to be significant. There are some results in which $\mathrm{P}$ is lower than 0.001 .

\section{RESULTS}

\subsection{Vascular Reactivity}

Forskolin induced relaxation in a concentration-dependent way in both endothelium intact and denuded rat aortic rings pre-contracted with phenylephrine. As shown in Figure 1(a), the maximum relaxant effect induced by forskolin $(103.8 \% \pm 2.5 \%, \mathrm{n}=6)$ was not changed by endothelium removal $(100 \%, n=6)$. However, the potency of forskolin in inducing the relaxation in the intact endothelium aortic rings $\left(\mathrm{pEC}_{50}: 7.18 \pm 0.05\right)$ decreased with endothelium removal to $6.99 \pm 0.06(\mathrm{P}<0.05)$ (Figure 1(b)). 


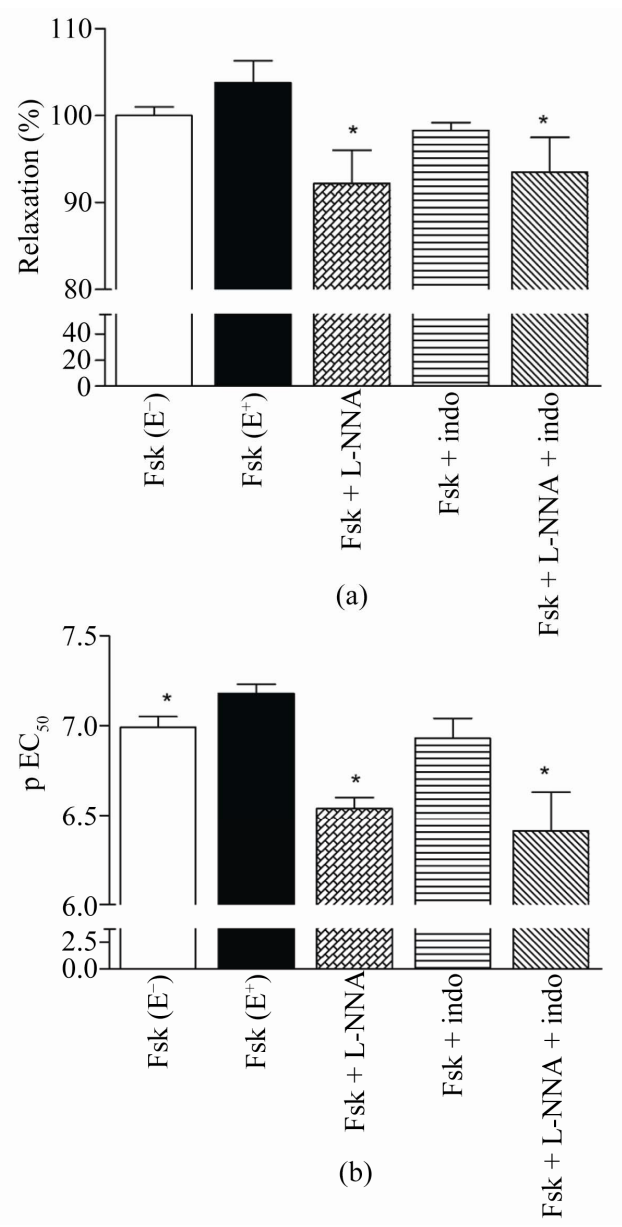

Figure 1. Relaxation induced by forskolin in rat denuded aortic rings $\left(\mathrm{E}^{-}\right)$, intact endothelium $\left(\mathrm{E}^{+}\right)$, or $\left(\mathrm{E}^{+}\right)$ plus L-NNA (Fsk + L-NNA), indomethacin (Fsk + indo) or both (Fsk + L-NNA + indo) pre-contracted with phenylephrine. Values are mean \pm S.E.M. $(n=6)$ of the maximal relaxant effect (Emax) (a) and potency $\left(\mathrm{pEC}_{50}\right)$ (b). ${ }^{*}$ denotes significant $(\mathrm{P}<0.05)$ difference in relation to Fsk $\left(\mathrm{E}^{+}\right)$.

In order to evaluate whether the production of the relaxant endothelial factors $\mathrm{NO}$ and $\mathrm{PGI}_{2}$ are involved in the forskolin-induced relaxation, the intact endothelium aortic rings were incubated with the inhibitors L-NNA, indomethacin or the combination of both inhibitors. LNNA $(10 \mu \mathrm{M})$ reduced both the maximum effect induced by forskolin to $92.2 \% \pm 3.8 \%(\mathrm{n}=6, \mathrm{P}<0.05)$ (Figure 1(a)) and its potency $\left(\mathrm{pEC}_{50}: 6.54 \pm 0.06, \mathrm{P}<0.001\right)$ (Figure 1(b)). On the other hand, indomethacin $(10 \mu \mathrm{M})$ did not alter the maximum effect $(98.3 \% \pm 0.9 \%, \mathrm{n}=6)$ (Figure 1(a)) nor its potency $\left(\mathrm{pEC}_{50}: 6.93 \pm 0.11\right)$ (Figure 1(b)). The combination of L-NNA $(10 \mu \mathrm{M})$ and indomethacin $(10 \mu \mathrm{M})$ reduced the maximum relaxant effect of forskolin $(93.5 \% \pm 4.0 \%, \mathrm{n}=6, \mathrm{P}<0.05)$ (Figure 1(a)) and its potency $\left(\mathrm{pEC}_{50}: 6.41 \pm 0.22, \mathrm{P}<0.01\right)$ (Figure 1(b)).

\subsection{Measurement of Cytosolic $\mathrm{Ca}^{2+}$ Concentration in the Aortic Endothelial Cells}

In the isolated rat aortic endothelial cells, forskolin (1 $\mu \mathrm{M})$ elicited significant increase in the fluorescence intensity of Fura-2AM, from $0.924 \pm 0.104$ (basal fluorescence) to $1.164 \pm 0.015$ units $(\mathrm{P}<0.01)$.

\subsection{Measurement of Cytosolic NO Concentration in the Aortic Endothelial Cells Using Confocal Microscopy}

As shown in Figures 2(a)-(f), forskolin $(1 \mu \mathrm{M})$ increase significantly the fluorescence intensity induced by the dye DAF-2T from 0 to $153.3 \% \pm 10.5 \%(\mathrm{n}=4, \mathrm{P}<$ $0.001)$, which indicates an increase in $[\mathrm{NO}] \mathrm{c}$ over the basal levels. In endothelial cells pre-incubated with L-NNA $(5 \mu \mathrm{M})$, forskolin decreased fluorescence of the dye DAF-2T, related with forskolin-induced NO production from 0 to $-5.9 \% \pm 1.2 \%(\mathrm{n}=3, \mathrm{P}<0.001)$, below the basal level shown in the graph of Figure 2(g).

\subsection{Measurement of Cytosolic NO Concentration in the Aortic Endothelial Cells Using Flow Cytometry}

In order to evaluate the effect of the inhibition of PKA in a larger number of endothelial cells, it was used flow cytometry in a time-dependent effect of forskolin. Forskolin $(1 \mu \mathrm{M})$ elicited significant increase in the fluorescence of the dye DAF-2T (blank) in relation to the time immediately after forskolin addition to the cells (time 0: $89.7 \% \pm 12.6 \%(\mathrm{n}=3, \mathrm{P}<0.01)$; after 5 min it was increased to $153.8 \% \pm 11.0 \%(\mathrm{n}=3, \mathrm{P}<0.01)$ and after 10 min it was increased to $224.6 \% \pm 27.3 \%(\mathrm{n}=3, \mathrm{P}<0.01)$. The treatment of the cells with KT5720 (10 $\mu \mathrm{M})$ inhibited the effect of forskolin in increasing [NO]c with the IF of $60.3 \% \pm 1.0 \%$ at $\mathrm{T} 0(\mathrm{n}=3, \mathrm{P}<0.05)$, after $5 \mathrm{~min}$ $(107.9 \% \pm 5.4 \%, \mathrm{n}=3, \mathrm{P}<0.004)$, and after $10 \mathrm{~min}$ $(168.4 \% \pm 15.5 \%, \mathrm{n}=3, \mathrm{P}<0.05)$ (Figure 3$)$ in relation to forskolin.

\subsection{Measurement of [cGMP]c Content}

As shown in Figure 4, forskolin elicited a significant increase in cGMP production ( $28.0 \pm 1.8$ fmol of protein) as compared to the basal levels in homogenized vessel containing intact endothelium $\left(\mathrm{E}^{+}\right)(16.2 \pm 1.8 \mathrm{fmol}$ of protein) $(\mathrm{P}<0.05)$. The production of cGMP stimulated with forskolin was significantly inhibited by L-NNA $(18.8 \pm 0.4$ fmol of protein $)(\mathrm{P}<0.05)$, which values were comparable to the basal levels.

\section{DISCUSSION}

The major finding of this study is that vasodilatation 

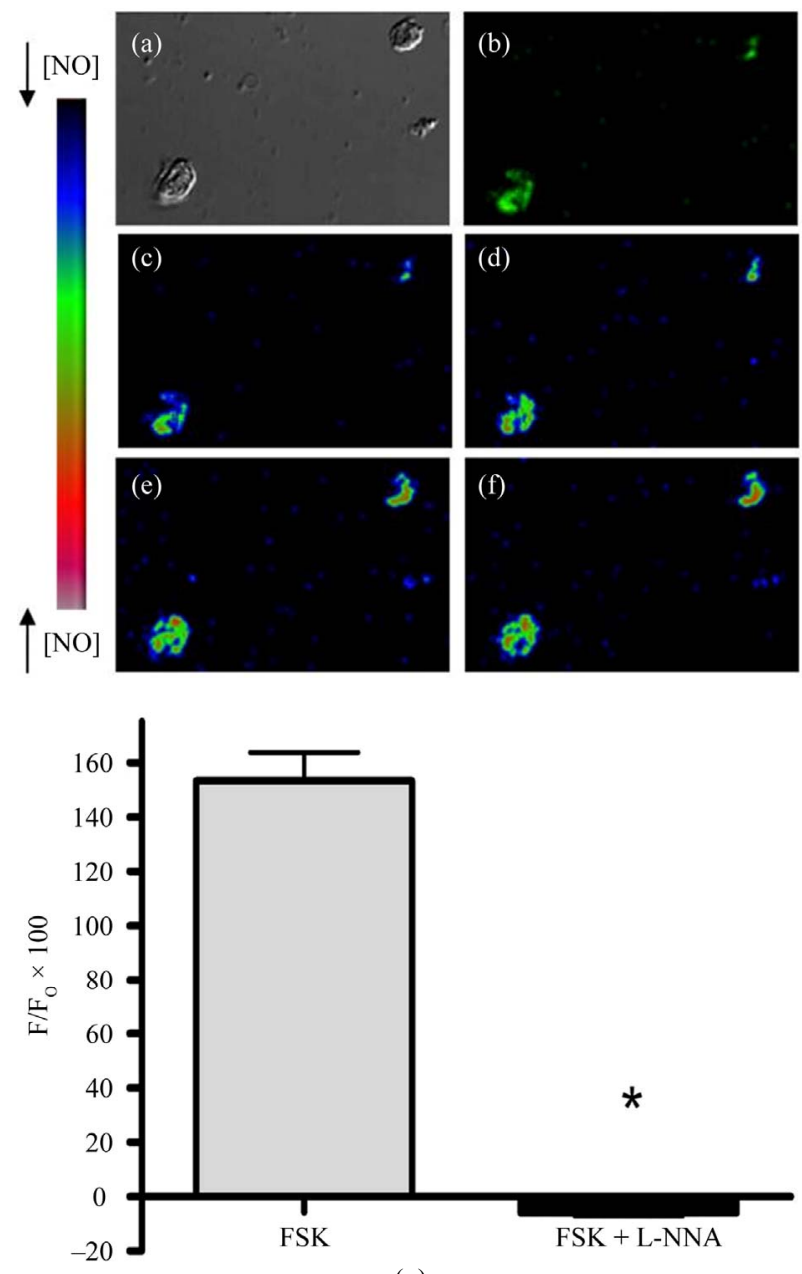

(g)

Figure 2. Effect of forskolin in the fluorescence intensity induced by DAF-2DA in endothelial cells with and without L-NNA. (a)-(b) Image in differential contrast phase-DIC, image of DAF fluorescence and time series image in pseudocolor. (c)-(f) Serial NO images of DAF-2T fluorescence in endothelial cells were recorded at: $t=0,20,60$ and 120 seconds after addition of Fsk. The arbitrary intensity values from low and high [NO] are indicated by pseudocolor values. $(\mathrm{g})$ Values are mean \pm S.E.M. $(n=3)$ obtained from 3 different animals and after incubation with L-NNA for $5 \mathrm{~min}$ and then stimulated with forskolin. *Denotes significant $(\mathrm{P}<0.001)$ difference between basal and stimulated cells.

induced by forskolin involves cyclic GMP production. These results are supported by the observation that forskolin elicited NO production in rat aortic endothelial cells that induces smooth muscle relaxation.

It is well known that many agents are able to elevate intracellular cAMP content [18]. Ours results show that forskolin is similarly effective in induce relaxation of intact endothelium or denuded rat aortic rings. These data demonstrate that the rat aortic smooth muscle cells relaxation elicited with forskolin occurs in spite of the endothelium, although this vasorelaxation induced by for-

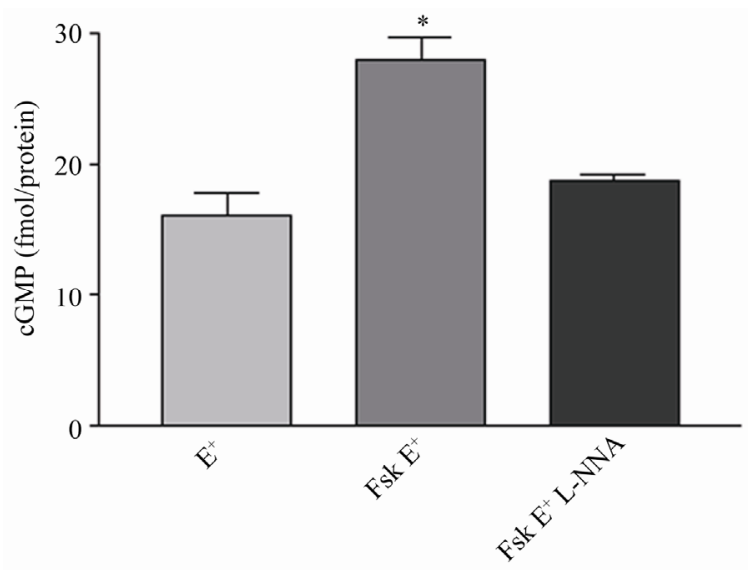

Figure 3. Effect of KT5720 on the fluorescence induced by DAF-2DA in endothelial cells stimulated with forskolin in the absence (Fsk) or in the presence of $10 \mu \mathrm{M}$ KT5720 (Fsk + KT5720), in $\mathrm{Ca}^{2+}$-free PSS. Values were obtained at different times after addition of forskolin at $t=0,5$ and 10 minutes. Values are mean \pm S.E.M. $(n=3)$ obtained from different animals. $*(\mathrm{P}<0.05)$ denotes significant difference between Fsk and Fsk + KT5720 in each time of incubation.

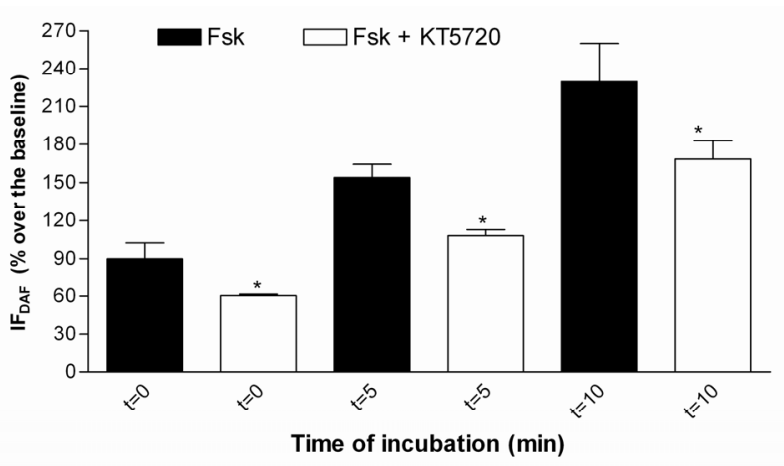

Figure 4. Production of tissue cGMP by forskolin in intact endothelium rat aorta. Aortic rings were treated or not (basal) with forskolin for $10 \mathrm{~min}\left(\mathrm{Fsk} \mathrm{E}^{+}\right)$, or forskolin $(10 \mathrm{~min})+$ L-NNA $(10 \mathrm{~min})\left(\mathrm{Fsk} \mathrm{E}^{+}+\mathrm{L}-\mathrm{NNA}\right)$. Values are the mean \pm S.E.M. from three independent determinations. ${ }^{*} \mathrm{P}<0.05$ denotes significant difference between for cGMP production in relation to Fsk $\left(\mathrm{E}^{+}\right)$.

skolin is potentiated by endothelial factors.

The backgrounds of literature and our results indicate the role of vascular endothelial factors on the increased sensitivity of rat aortic rings to forskolin. Thus, the effect of inhibition of NO production on this relaxation by using an analog of the substrate of eNOS (L-NNA) inhibits the specific conversion of L-arginine to NO [19]. The vasorelaxant effect of forskolin was blunted with L-NNA in endothelium-intact aortic rings. Since the inhibitory effect of L-NNA on the relaxation induced by forskolin is more pronounced in intact endothelium than that obtained in denuded aortic rings stimulated with forskolin, 
it is possible to suppose that forskolin elicits NO production in the smooth muscle cells.

It was previously reported by Koide et al. (1993) [20] that the iNOS expression is positively regulated by cAMP and may represent an unrecognized mechanism by which cAMP-elevating vasodilators can cause more prolonged and potent cell responses, that is supported by Imai et al. (1994) [21], Nakayama et al. (1995) [22] and Ikeda et al. (1996) [23].

In the present study, it is described an increase in cytosolic $\mathrm{Ca}^{2+}$ concentration in the endothelial cells stimulated with forskolin that can activate eNOS through the $\mathrm{Ca}^{2+}$-calmodulin complex, which results in NO production. As described by Berkels et al. (2000) [24], NO production in vascular endothelial cell occurs simultaneously to the increase of intracellular $\mathrm{Ca}^{2+}$. Stevens et al. (1997) [25] had already shown that the increase of cAMP, via activation of isoform III enzyme adenylyl-cyclase, is related to increased $\mathrm{Ca}^{2+}$ cytosol in some phenotypes of cells, such as vascular endothelium of rats [26], where six of these isoforms (types II-VI and VIII) can be found.

Thus, we suggest that the increased relaxant effect of forskolin in aortic rings is related to the activation of NO production in the endothelial cells, which was evaluated by the increase of NO production observed by the cell images obtained in the confocal microscope. Therefore, the cells incubated with L-NNA showed that forskolin activates NO production in rat aortic endothelial cells, since the fluorescence of the selective NO probe was decreased under the baseline.

It has been also reported that eNOS can be phosphorylated by several protein kinases including PKA [12, 27]. In order to verify whether forskolin can directly activate the NO production via PKA, we have studied the effect of the PKA inhibitor KT5720 in the endothelial cells stimulated with forskolin in $\mathrm{Ca}^{2+}$-free medium to exclude a $\mathrm{Ca}^{2+}$-dependent mechanism on the production of NO activated by PKA. Under these conditions, a decreased-DAF-2T fluorescence was observed in endothelial cells suggesting that at least in part the NO production stimulated with forskolin in endothelial cells is due to activation of PKA. Hashimoto et al. (2006) [28] observed that the increase in NO production was elicited by cilostazol, forskolin, cilostamide, and rolipram. These authors suggested these agents that elevate cAMP leves, induces NO production by eNOS activation via a cAMP/ PKA- and PI3K/Akt-dependent mechanism in capillarylike tube formation in human aortic endothelial cells.

In this work, we evaluated the effect of indomethacin, in order to investigate the contribution of the produced $\mathrm{PGI}_{2}$ to the relaxation activated by forskolin. Indomethacin did not change forskolin-induced relaxation, which suggests that the relaxation induced by forskolin does not involve $\mathrm{PGI}_{2}$ production in the endothelial cells. Moreover, in the present study we demonstrate that the combination of the inhibitors L-NNA (eNOS) and indomethacin (ciclooxigenase) generates similar effects to L-NNA alone.

In summary, the relaxation induced by forskolin can be related to increased cytosolic $\mathrm{Ca}^{2+}$ concentration and NO production in the endothelial cells. At least two mechanisms could be involved: a $\mathrm{Ca}^{2+}$-dependent pathway that it is indirectly activated by PKA $[29,30]$, and/or a $\mathrm{Ca}^{2+}$-independent pathway modulated by direct activation of eNOS by PKA [12,27,31]. Therefore, it can be suggested that the direct activation of adenylyl cyclase by forskolin could mediate both processes.

\section{CONCLUSIONS}

Taken together, our results indicate that vasodilatation stimulated with forskolin in rat aortic rings is potentiated by NO produced in the endothelial cells resulting in increased production of cGMP in the smooth muscle cells. Then, cAMP along with cGMP induces vascular smooth muscle cells relaxation stimulated with forskolin.

\section{ACKNOWLEDGEMENTS}

This study was supported by grants from FAPESP and CNPq. We thank Juliana C. Vercesi and Fabiana R. de Morais for technical assistance, and Confocal Microscopy Facility at the Faculdade de Medicina de Ribeirão Preto, Universidade de São Paulo.

\section{REFERENCES}

[1] Kukovetz, W.R., Poch, G. and Wurm, A. (1975) Quantitative relations between cyclic AMP and contraction as affected by stimulators of adenylate cyclase and inhibitors of phosphodiesterase. Advances in Cyclic Nucleotide Research, 5, 395-414.

[2] Seamon, K.B. and Daly, J.W. (1981) Forskolin: A unique diterpene activator of cyclic AMP-generating systems. Proceedings of the National Academy of Sciences of the United States of America, 78, 3363-3367. doi:10.1073/pnas.78.6.3363

[3] Laurenza, A., Khandelwal, Y., De Souza, N.J., Rupp, R.H., Metzqer, H. and Seamon, K.B. (1987) Stimulation of adenylate cyclase by water-soluble analogues of forskolin. Molecular Pharmacology, 32, 133-139.

[4] Muller, M.J. and Baer, H.P. (1983) Relaxant effects of forskolin in smooth muscle. Role of cyclic AMP. NaunynSchmiedeberg's Archives of Pharmacology, 322, 78-82. doi:10.1007/BF00649356

[5] Manolopoulos, V.G., Pipili-Synetos, E., Den Hertog, A. and Nelemans, A. (1991) Inositol phosphates formed in rat aorta after alpha 1-adrenoceptor stimulation are inhibited by forskolin. European Journal of Pharmacology, 207, 29-36. doi:10.1016/S0922-4106(05)80034-3

[6] Meisheri, K.D. and van Breemen, C. (1982) Effects of beta-adrenergic stimulation on calcium movements in 
rabbit aortic smooth muscle: Relationship with cyclic AMP. The Journal of Physiology, 331, 429-441.

[7] Bhalla, R.C., Webb, R.C., Singh, D. and Brock, T. (1978) Role of cyclic AMP in rat aortic microsomal phosphorylation and calcium uptake. American Journal of Physiology, 234, H508-H514.

[8] Conti, M.A. and Adelstein, R.S. (1981) The relationship between calmodulin binding and phosphorylation of smooth muscle myosin kinase by the catalytic subunit of 3':5' cAMP-dependent protein kinase. The Journal of Biological Chemistry, 256, 3178-3181.

[9] Scheid, C.R. and Fay, F.S. (1984) Beta-adrenergic effects on transmembrane $45 \mathrm{Ca}$ fluxes in isolated smooth muscle cells. American Journal of Physiology, 246, C431-C438.

[10] Moncada, S., Palmer, R.M. and Higgs, E.A. (1991) Nitric oxide: Physiology, pathophysiology, and pharmacology. Pharmacological Reviews, 43, 109-142.

[11] Lowenstein, C.J. and Snyder, S.H. (1992) Nitric oxide, a novel biologic messenger. Cell, 70, 705-707. doi:10.1016/0092-8674(92)90301-R

[12] Boo, Y.C., Sorescu, G.P., Bauer, P.M., Fulton, D., Kemp, B.E., Harrison, D.G., Sessa, W.C. and Jo, H. (2003) Endothelial NO synthase phosphorylated at ser635 produces NO without requiring intracellular calcium increase. Free Radical Biology \& Medicine, 35, 729-741. doi:10.1016/S0891-5849(03)00397-6

[13] Moncada, S. and Vane, J.R. (1979) The role of prostacyclin in vascular tissue. Desty's Federal Procedure, 38, 66-71.

[14] Samokovlisky, A., Rimon, G. and Danon, A. (1999) Differential regulation of cyclooxygenase isoenzymes by cAMPelevating agents. European Journal of Pharmacology, 378, 203-211. doi:10.1016/S0014-2999(99)00461-6

[15] Dias, K.L., Correia, N.A., Pereira, K.K., Barbosa-Filho, J.M., Cavalcante, K.V., Araújo, I.G., Silva, D.F., Guedes, D.N., Neto, M.A., Bendhack, L.M. and Medeiros, I.A. (2007) Mechanisms involved in the vasodilator effect induced by diosgenin in rat superior mesenteric artery. European Journal of Pharmacology, 574, 172-178. doi:10.1016/j.ejphar.2007.07.017

[16] Kojima, H., Nakatsubo, N., Kikuchi, K., Kawahara, S., Kirino, Y., Nagoshi, H., Hirata, Y. and Nagano, T. (1998) Detection and imaging of nitric oxide with novel fluorescent indicators: Diaminofluoresceins. Analytical Chemistry, 70, 2446-2453. doi:10.1021/ac9801723

[17] Rodrigues, G.J., Lunardi, C.N., Lima, R.G., Santos, C.X., Laurindo, F.R.M., Silva, R.S. and Bendhack, L.M. (2008) Vitamin C improves the effect of a new nitric oxide donor on the vascular smooth muscle from renal hypertensive rats. Nitric Oxide, 18, 176-183. doi:10.1016/j.niox.2007.12.002

[18] Murray, K.J. (1990) Cyclic AMP and mechanism of vasodilatation. Pharmacology \& Therapeutics, 47, 329345. doi:10.1016/0163-7258(90)90060-F

[19] McCall, T.B., Feelisch, M., Palmer, R.M. and Moncada, S. (1991) Identification of N-iminoethyl-L-ornithine as an irreversible inhibitor of nitric oxide synthase in phagocytic cells. European Journal of Pharmacology, 102, 234 -238 .

[20] Koide, M., Kawahara, Y., Nakayama, I., Tsuda, T. and
Yokohama, M. (1993) Cyclic AMP-elevating agents induce an inducible type of nitric oxide synthase in cultured vascular smooth muscle cells. Synergism with the induction elicited by inflammatory cytokines. The Journal of Biological Chemistry, 268, 24959-24966.

[21] Imai, T., Hirata, Y., Kanno, K. and Marumo, F. (1994) Induction of nitric oxide synthase by cyclic AMP in rat vascular smooth muscle cells. The Journal of Clinical Investigation, 93, 543-549. doi:10.1172/JCI117005

[22] Nakayama, I., Kawahara, Y., Tsuda, T., Koide, M. and Yokohama, M. (1995) Cyclic AMP elevating agents synergize with inflammatory cytokines to induce an inducible type of nitric oxide synthase in cultured vascular smooth muscle cells. Annals of the New York Academy of Sciences, 748, 586-589. doi:10.1111/j.1749-6632.1994.tb17366.x

[23] Ikeda, U., Kanbe, T. and Shimada, K. (1996) Adrenomedullin increases inducible Nitric oxide synthase in rat vascular smooth muscle cells stimulated with interleukin1. Hypertension, 27, 1240-1244.

[24] Berkels, R., Dachs, C., Roesen, R. and Klaus, W. (2000) Simultaneous measurement of intracellular $\mathrm{Ca}^{2+}$ and nitric oxide: A new method. Cell Calcium, 27, 281-286. doi:10.1054/ceca.2000.0119

[25] Stevens, T., Fouty, B., Hepler, L., Richardson, D., Brough, G., McMurtry, I.F. and Rodman, D.R. (1997) Cytosolic $\mathrm{Ca}^{2+}$ and adenylyl cyclase responses in phenotypically distinct pulmonary endothelial cells. Lung Physiology, 272, L51-L59.

[26] Manolopaulos, V.G., Liu, J., Unsworth, B.R. and Lelkes, P.I. (1995) Adenylyl cyclase isoforms are differentially expressed in primary cultures of endothelial cells and whole tissue homogenates from various rat tissues. Biochemical and Biophysical Research Communications, 208, 323-331. doi:10.1006/bbrc.1995.1341

[27] Chen, Z.P., Mitchelhill, K.I., Michell, B.J., Stapleton, D., Rodriguez-Crespo, I., Witters, L.A., Power, D.A., Ortiz de Montellano, P.R. and Kemp, B.E. (1999) AMP-activated protein kinase phosphorylation of endothelial NO synthase. FEBS Letters, 443, 285-289. doi:10.1016/S0014-5793(98)01705-0

[28] Hashimoto, A., Miyakoda, G., Hirose, Y. and Mori, T. (2006) Activation of endothelial nitric oxide synthase by cilostazol via a cAMP/protein kinase A- and phosphatidy- linositol 3-kinase/Akt-dependent mechanism. Athero- sclerosis, 189, 350-357. doi:10.1016/j.atherosclerosis.2006.01.022

[29] Bredt, D.S. and Snyder, S.H. (1990) Isolation of nitric oxide synthetase, a calmodulin-requiring enzyme. Proceedings of the National Academy of Sciences of the United States of America, 87, 682-685. doi:10.1073/pnas.87.2.682

[30] Govers, R. and Rabelink, T.J. (2001) Cellular regulation of endothelial nitric oxide synthase. American Journal of Physiology Renal Physiology, 280, F193-F206.

[31] Michel, T., Li, G.K. and Busconi, L. (1993) Perspective series: Nitric oxide and nitric oxide synthases-nitric oxide synthases: Which, where, how and why? Proceedings of the National Academy of Sciences of the United States of America, 90, 6252-6256. doi:10.1073/pnas.90.13.6252 